\title{
In Vitro Evaluation of the Staining Effects of Two Intracanal Medicaments over a 3-Month Period
}

\author{
Taxiarchis G. Kontogiannis*, Anastasios Koursoumis, Nikolaos P. Kerezoudis \\ Department of Endodontics, Athens Dental School, University of Athens, Athens, Greece \\ Email: "tkontogiannis@hotmail.com
}

Received 29 May 2014; revised 19 July 2014; accepted 1 August 2014

Copyright (C) 2014 by authors and Scientific Research Publishing Inc.

This work is licensed under the Creative Commons Attribution International License (CC BY).

http://creativecommons.org/licenses/by/4.0/

(c) (i) Open Access

\begin{abstract}
Aim: The aim of this study was to evaluate in vitro the tooth color alterations associated with two intracanal medicaments, calcium hydroxide and calcium hydroxide combined with aquatic solution of chlorexidine, for up to three months post-treatment. Materials \& Methods: Thirty-one intact human anterior mature teeth were used. Black adhesive tape with a 4-mm diameter window was used to standardize the enamel surface intended for color analysis. After access cavity preparation, cleaning and shaping were completed with rotary nickel-titanium files. The teeth were randomly divided into two groups $(n=15)$, each according to the intracanal medicament used: $(A)$ calcium hydroxide paste (UltraCal ${ }^{\mathrm{TM}} \mathrm{XS}^{\mathrm{TM}}$ Ultradent Products, Inc., USA); (B) $2 \%$ chlorhexidine aquatic solution combined with pure calcium hydroxide powder. In one tooth, no medicament was placed (pilot). The enamel surfaces were colormetrically evaluated at the following time intervals: before placing the medicaments, immediately after placement, after 1 week as well as after 1,2 and 3 months post-treatment. The CIE color parameters $\left(L^{*}, a^{*}, b^{*}\right)$ were recorded for each material and the corresponding color differences $(\Delta E)$ were calculated and statistically analyzed. Results: The most significant factor in tooth discoloration was the time intervals. The most important changes of the $\Delta E$ values were recorded after the 1 st week and after the $3 r d$ month. $L^{*}$ presented an overall increase in both groups, resulting in a higher lightness of the crown color. Only $\mathrm{L}^{*}$ did show significant alterations during specific time intervals. Conclusions: There is no statistically significant relationship between the type of intracanal medicament and tooth color alteration. Time is statistically the most important factor affecting the discoloration ability of $\mathrm{Ca}(\mathrm{OH})_{2}$, either combined with chlorexidine or not. Consequently, the clinician should always take this into account before using such medicaments for a long-term treatment.
\end{abstract}

\section{Keywords}

Calcium Hydroxide, Chlorexidine, Intracanal Medicaments, Discoloration

\footnotetext{
*Corresponding author.
}

How to cite this paper: Kontogiannis, T.G., Koursoumis, A. and Kerezoudis, N.P. (2014) In Vitro Evaluation of the Staining Effects of Two Intracanal Medicaments over a 3-Month Period. Open Journal of Stomatology, 4, 381-388. 


\section{Introduction}

Tooth discoloration is a possible side effect of endodontic treatment of anterior teeth [1]. Hemorrhage inside the pulp cavity, residual pulpal tissue as well as materials used during root canal treatment are the most usual causes for discoloration [2]. In addition obturating materials, intracanal medicaments and temporary filling materials may cause also of internal tooth staining [1]-[3]. As far as the intracanal medicaments concerns, their role in the success of the endodontic treatment is important, since they maintain the root canals disinfected for the time interval between instrumentation and final root canal obturation [4].

Calcium hydroxide $\left(\mathrm{Ca}(\mathrm{OH})_{2}\right)$ plays an important role in endodontics due to its ability to induce hard tissue formation, its antibacterial effect and its ability to act as a physical barrier to prevent root canal reinfection [4] [5]. These properties derive from its high $\mathrm{pH}$ (up to 12.5), which neutralises lactic acid from the osteoclasts, thus preventing a dissolution of the mineral components of dentin. Moreover, it could also activate alkaline phosphatases which play an important role in hard tissue formation [5] [6]. However, due to the existence of $\mathrm{Ca}(\mathrm{OH})_{2^{-}}$ resistant micro-organisms (especially E. faecalis), many antimicrobial agents have been proposed for use, in combination with $\mathrm{Ca}(\mathrm{OH})_{2}[4]$ [5] [7].

One of the most important antimicrobial agents in dentistry is chlorexidine (CHX). The most significant properties that justify the use of CHX as an intracanal medicament are its antimicrobial activity against Grampositive and Gram-negative microorganisms, as well as its residual antimicrobial ability on the dentin surface after remaining for at least one week within the root canal (substantivity) [4] [8]. Moreover, CHX is effective against bacteria that are resistant to $\mathrm{Ca}(\mathrm{OH})_{2}$ and mainly E. faecalis; this property justifies the use of $\mathrm{CHX}$ in retreatments, where such bacteria are usually found [9]. However, clinical studies have recorded tooth staining by CHX, especially when it is used as a mouthrinse for periodontal treatment [8] [10]. The most possible staining mechanisms of tooth discolorations due to CHX application seem to be non-enzymatic browning (Maillard reactions) and formation of pigmented black metal sulfides [10]. Nevertheless, the corresponding phenomenon has not been investigated in cases when CHX is used for endodontic purposes. On the contrary, the staining potential of $\mathrm{Ca}(\mathrm{OH})_{2}$ has not been clearly defined, as its discoloration ability may depend on its chemical composition (pure $\mathrm{Ca}(\mathrm{OH})_{2}$ powder, or commercial $\mathrm{Ca}(\mathrm{OH})_{2}$ pastes whose some contents may be able to discolor teeth). Nevertheless, some latest studies have concluded that $\mathrm{Ca}(\mathrm{OH})_{2}$ has indeed a discoloration potential, which might not have been extensively taken into account up to date [1]-[3]. The exact staining mechanism of $\mathrm{Ca}(\mathrm{OH})_{2}$ is not clearly known; it has been implied that it is more likely due to any additional components, i.e. bismuth carbonate, that usually exist in many commercially-prepared $\mathrm{Ca}(\mathrm{OH})_{2}$ pastes [3], while as regards pure $\mathrm{Ca}(\mathrm{OH})_{2}$ powder, there has not been a convincing explanation.

The aim of this study was an ex vivo assessment of the discoloration potential of two different intracanal medicaments: (A) $\mathrm{Ca}(\mathrm{OH})_{2}$, (B) $\mathrm{Ca}(\mathrm{OH})_{2}$ combined with aquatic solution of $\mathrm{CHX}$, both evaluated over a 3-month period. The hypothesis tested was that $\mathrm{Ca}(\mathrm{OH})_{2}$ and the combination of $\mathrm{Ca}(\mathrm{OH})_{2}$ with $\mathrm{CHX}$ as single intracanal medicaments did not present differences neither between nor in relation to the absence of any medicament as regards tooth color changes induced within 3-month post-treatment.

\section{Materials and Methods}

Thirty one intact human anterior mature teeth extracted for periodontal reasons were initially stored in $10 \%$ formalin. The teeth were free of caries, restorations and coronal staining. The teeth were cleaned with ultrasonics to disclose gross debris, followed by brushing with a rubber cup and pumice in order to remove remaining debris and stains from the coronal crown surface. Thereafter, the teeth were kept in distilled water until use.

To monitor the color changes of the teeth the method described by Koursoumis et al. was used [11]. Briefly, on a black rectangular piece of adhesive tape, a round opening of $4 \mathrm{~mm}$ in diameter was cut so as to match the size of the window of the colorimeter apparatus. The black tape was applied on the facial aspect of the crown in such a way that the round opening was positioned on the cervical third of the crown (Figure 1).

After the preparation of an access cavity of each tooth, the canal was negotiated with a stainless steel size \#10 K-file (Dentsply Maillefer, Baillaigues, Switzerland) and the working length was determined by subtracting $1 \mathrm{~mm}$ of the file length when the tip was visible on the apical foramen. Then, a glide path was confirmed using stainless steel size \#15 and \#20 K-files (Dentsply Maillefer, Baillaigues, Switzerland) in conjunction with copious amounts of irrigation. $2.5 \% \mathrm{NaOCl}$ was used as irrigant in all teeth. Canal shaping was performed with a WaveOne large Ni-Ti rotary instrument (Tulsa Dentsply, Tulsa, OK, USA) used in a reciprocating movement 


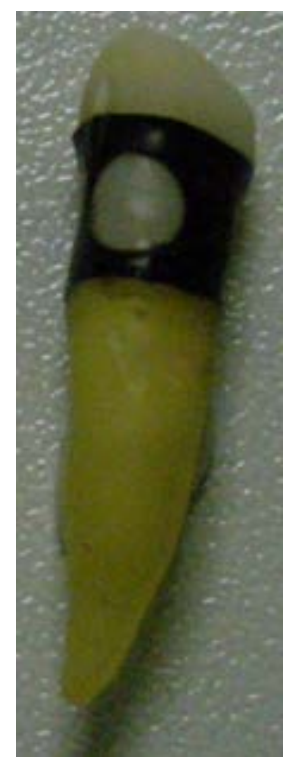

Figure 1. One of the specimens with its black rectangular piece of adhesive tape and the round opening on it to match the size of the colorimeter aparatus; the black tape was applied on the facial aspect of the crown in such a way that the round opening was positioned on the cervical third of the crown.

under copious irrigation. The large WaveOne instrument has similar conicity with the F2 ProTaper instrument. All instruments were used in conjunction with a 16:1 reduction ratio contra-angle connected to an ATR Vision (ATR, Pistoia, Italy) motor which allows the reciprocating movement. The clockwise and the counter-clockwise rotations are set on the motor at four-tenth and two-tenth of a circle. The rotational speed was set at $400 \mathrm{rpm}$.

After cleaning and shaping, one tooth was irrigated with $2.5 \% \mathrm{NaOCl}$, dried with air and paper points and its pulp chamber was sealed with a sterile cotton pellet, without any intracanal medicament (pilot tooth). The rest thirty teeth were randomly divided into two groups $(n=15)$, each according to the intracanal medicament used; (A) $\mathrm{Ca}(\mathrm{OH})_{2}$ paste (UltraCal ${ }^{\mathrm{TM}} \mathrm{XS}^{\mathrm{TM}}$ Ultradent Products, Inc. USA), (B) $2 \%$ chlorhexidine aquatic solution combined with pure $\mathrm{Ca}(\mathrm{OH})_{2}$ powder. In group $\mathrm{A}$, after copious irrigations with $\mathrm{NaOCl}$, the pulp chamber and the root canals were slightly dried with air and the excess of the irrigant was removed with paper points, followed by the placement of the $\mathrm{Ca}(\mathrm{OH})_{2}$ paste and the removal of any excess of the medicaments in the access cavity. In group B, after copious irrigations with chlorexidine, the pulp chamber and the root canals were slightly dried with air and the excess of the irrigant was removed with paper points. After that, the combination of $\mathrm{Ca}(\mathrm{OH})_{2}$ with $\mathrm{CHX}$ was placed as follows: the $\mathrm{CHX}$ aquatic solution was prepared by a chemist by mixing chemically pure $\mathrm{CHX}$ with distilled water. Then, pure $\mathrm{Ca}(\mathrm{OH})_{2}$ powder was mixed with a few drops of the solution - with the exactly same way as $\mathrm{Ca}(\mathrm{OH})_{2}$ powder is mixed with saline-resulting in a thick mixture and applied to the root canals with a Lentulo spiral. Any excess of the medicaments were removed from the pulp chamber with a small cotton pellet and distilled water; afterwards, a sterile cotton pellet was enclosed in the pulp chamber in order to seal the access opening. All thirty one specimens were stored individually in a moist environment with $100 \%$ humidity in plastic airtight pouches, at a constant temperature of $37^{\circ} \mathrm{C}$. This methodology was studied thoroughly by other authors in the past [11] [12].

The color of the exposed enamel window through the tape hole was evaluated by a colorimeter apparatus (Microcolor, Data Station, DrLange, Braiveinstuments, Liege, Belgium) according to CIE Lab system (CIE L*, $\left.a^{*}, b^{*}\right)$ employing a repeated measurements design $(n=3)$. In order to establish an accurate positioning system for consistent assessments during color measurements, the specimens were mounted on silicon templates. Tooth color was measured before the application of medicaments (reference color), immediately after their application (baseline), and 1 week, 1 month, 2 months and 3 months post-treatment. The $\Delta \mathrm{L}^{*}, \Delta \mathrm{a}^{*}$ and $\Delta \mathrm{b}^{*}$ values were calculated by subtracting the reference value from the values of each time post-treatment. The $\Delta \mathrm{E}$ values, which were used to measure the color changes, were calculated by the equation $\Delta \mathrm{E}=\left[\Delta \mathrm{L}^{* 2}+\Delta \mathrm{a}^{* 2}+\Delta \mathrm{b}^{* 2}\right]^{1 / 2}$ (Bureau Central de la Commision Internationale de l'Eclairage, 1978). According to the CIE system, $\mathrm{L}^{*}$ contributes to 
the black-to-white hue of the tooth, $a^{*}$ contributes to the red-to-green hue, $b^{*}$ to the yellow-to-blue hue, while $\Delta \mathrm{E}$ determines whether there is an overall color alteration [13].

The $\Delta \mathrm{E}$ values at the four post-treatment times were statistically analyzed by two-way ANOVA repeated test with endodontic intracanal medicament and post-treatment time as discriminating variables, following by Scheffé test $(\mathrm{p}<0.05)$. Two-way ANOVA repeated test was also applied to identify the changes in $\mathrm{L}^{*}, \mathrm{a}^{*}, \mathrm{~b}^{*}$ by means of post-treatment time followed by Scheffé test $(\mathrm{p}<0.05)$. Statistical analysis was performed using SPSS Statistics 17.0 software (SPSS, Inc., Chicago, IL, USA).

\section{Results}

Table 1 depicts the $\Delta \mathrm{E}$ values measured for the two medicaments $\left(\mathrm{Ca}(\mathrm{OH})_{2}, \mathrm{Ca}(\mathrm{OH})_{2}-\mathrm{CHX}\right)$ as well as the pilot tooth, at the four post-treatment times. Table 2 presents the $\mathrm{L}^{*}$, $\mathrm{a}^{*}$ and $\mathrm{b}^{*}$ values for the two medicaments and the pilot tooth, both at the four post-treatment times and the reference color before the application of the medicaments. A gradual reduction of the mean $\Delta \mathrm{E}$ values was recorded after the $1^{\text {st }}$ week. Furthermore, $\Delta \mathrm{E}$ values at the end of the observation period were above 3.3 for both groups, hence there was a color alteration probably perceivable even by a patient, as described above; on the contrary, the $\Delta \mathrm{E}$ values of the pilot tooth remained below 3.3 throughout the 3-month observation period.

Statistical analysis of $\Delta \mathrm{E}$ values showed that only time intervals have a significant effect on the $\Delta \mathrm{E}$ values; the type of medicament did not have a statistically significant effect on the color changes recorded (Table 3). Thus, Scheffé test was applied only to figure out any statistically significant differences in the $\Delta E, L^{*}$, $a^{*}$ and $b^{*}$ values. Indeed, significant changes of $\Delta \mathrm{E}$ values were recorded after the $1^{\text {st }}$ week and after the $3^{\text {rd }}$ month (Table 4). Statistical analysis of $L^{*}, a^{*}, b^{*}$ values showed that time intervals were again the only significant factor and interestingly, they affected only L* and a* parameters (Table 3). L* showed a significant change in the first week, while $\mathrm{a}^{*}$ showed a significant change in the $2^{\text {nd }}$ and $3^{\text {rd }}$ month, both compared to the reference color (Table 4).

\section{Discussion}

According to the results of the present study, no significant difference was noted between the two intracanal medicaments as concerns color alterations. However, both medicaments provided a significant color change compared to the pilot tooth in which no medicament was applied.

It is a common knowledge that many intracanal medicaments may result in tooth discoloration, but as regards $\mathrm{Ca}(\mathrm{OH})_{2}$, its possible impact on color alterations remains unclear [1]-[3]. Some in vitro studies showed that

Table 1. $\Delta \mathrm{E}$ values of the two endodontic medicaments $\left(\mathrm{Ca}(\mathrm{OH})_{2}, \mathrm{Ca}(\mathrm{OH})_{2}-\mathrm{CHX}\right)$ at the four post-treatment times. The $\Delta \mathrm{E}$ values of the pilot tooth are also depicted.

\begin{tabular}{|c|c|c|}
\hline Group & Post-treatment time & $\Delta \mathbf{E}($ mean $\pm \mathrm{SD})$ \\
\hline \multirow[t]{4}{*}{$\mathrm{Ca}(\mathrm{OH})_{2}$} & 1 week & $10.13 \pm 4.37$ \\
\hline & 1 month & $4.32 \pm 2.1$ \\
\hline & 2 months & $5.65 \pm 2.24$ \\
\hline & 3 months & $7.18 \pm 3.83$ \\
\hline \multirow[t]{4}{*}{$\mathrm{Ca}(\mathrm{OH})_{2}-\mathrm{CHX}$} & 1 week & $12.29 \pm 5.29$ \\
\hline & 1 month & $6.11 \pm 4.02$ \\
\hline & 2 months & $6.25 \pm 3.92$ \\
\hline & 3 months & $6.75 \pm 4.4$ \\
\hline \multirow[t]{4}{*}{ Pilot } & 1 week & 2.7 \\
\hline & 1 month & 1.81 \\
\hline & 2 months & 2.32 \\
\hline & 3 months & 1.61 \\
\hline
\end{tabular}


Table 2. L*, a* \& b* values of the two endodontic medicaments and the pilot tooth at the four post-treatment times.

\begin{tabular}{|c|c|c|c|c|}
\hline Post treatment time & CIE parameter & $\mathrm{Ca}(\mathrm{OH})_{2}$ & $\mathrm{Ca}(\mathrm{OH})_{2}-\mathrm{CHX}$ & Pilot \\
\hline \multirow[t]{3}{*}{ Reference color } & $\mathrm{L}^{*}$ & $49.6 \pm 8.86$ & $50.3 \pm 6.92$ & 54.3 \\
\hline & $a^{*}$ & $4.68 \pm 4.15$ & $7.03 \pm 3.67$ & 4.9 \\
\hline & $b^{*}$ & $5.58 \pm 3.81$ & $6.55 \pm 3.53$ & 13.4 \\
\hline \multirow[t]{3}{*}{1 week } & $\mathrm{L}^{*}$ & $43.24 \pm 6.3$ & $41.98 \pm 6.35$ & 53.6 \\
\hline & $a^{*}$ & $4.52 \pm 5.58$ & $5.26 \pm 2.7$ & 5.1 \\
\hline & $\mathrm{b}^{*}$ & $6.81 \pm 4.27$ & $7.18 \pm 3.63$ & 10.8 \\
\hline \multirow[t]{3}{*}{1 month } & $\mathrm{L}^{*}$ & $49.67 \pm 8.58$ & $49.08 \pm 7.7$ & 55.7 \\
\hline & $a^{*}$ & $4.01 \pm 4.01$ & $3.7 \pm 3.27$ & 5.2 \\
\hline & $b^{*}$ & $7.21 \pm 3.31$ & $7.94 \pm 4.26$ & 12.3 \\
\hline \multirow[t]{3}{*}{2 months } & $\mathrm{L}^{*}$ & $51.72 \pm 10.1$ & $49.41 \pm 6.02$ & 56.3 \\
\hline & $a^{*}$ & $1.26 \pm 3.61$ & $4 \pm 3.1$ & 5.5 \\
\hline & $\mathrm{b}^{*}$ & $8.16 \pm 3.51$ & $8.12 \pm 4.64$ & 12.4 \\
\hline \multirow[t]{3}{*}{3 months } & $\mathrm{L}^{*}$ & $53.82 \pm 10.9$ & $50.36 \pm 6.41$ & 55.9 \\
\hline & $a^{*}$ & $1.27 \pm 3.75$ & $3.95 \pm 3.22$ & 5 \\
\hline & $\mathrm{b}^{*}$ & $8.56 \pm 3.77$ & $8.52 \pm 5.04$ & 13.6 \\
\hline
\end{tabular}

Table 3. Results of the two-way ANOVA analysis with reference to the statistical significance (if any) of the $\Delta E, L^{*}, a^{*}$, and $\mathrm{b}^{*}$ values amongst the two groups with the respective intracanal medicament and the pilot tooth. The first row compares the effect of the medicament, the second one the effect of time at the four-times period and the third one the combined effect of medicament and time. Statistically significant differences are marked in bold.

\begin{tabular}{cccccc}
\hline \multirow{2}{*}{ Factor } & \multicolumn{3}{c}{ Significance per value } \\
\cline { 2 - 5 } & $\mathbf{\Delta E}$ & $\mathbf{L}^{*}$ & $\mathbf{a}^{*}$ & 0.559 \\
Medicament type & 0.166 & 0.308 & 0.111 & $\mathbf{0}$ & 0.167 \\
Time & $\mathbf{0 . 0 0 0 2}$ & $\mathbf{0 . 0 0 0 3}$ & $\mathbf{0 . 0 0 5}$ & 0.986 \\
\hline Medicament*time & 0.592 & 0.893 & 0.463 & \\
\hline
\end{tabular}

Table 4. Results of the Scheffé test analysis with reference to the statistical significance (if any) of the $\Delta E, L^{*}, a^{*}$, and $b^{*}$ values amongst the two groups with the respective intracanal medicament according to the four post-treatment times (each value is compared at each time point to the reference color). Statistically significant differences are marked in bold.

\begin{tabular}{|c|c|c|c|c|c|}
\hline \multirow{2}{*}{\multicolumn{2}{|c|}{ Time intervals }} & \multicolumn{4}{|c|}{ Significance per value } \\
\hline & & $\Delta \mathbf{E}$ & $\mathbf{L}^{*}$ & $\mathbf{a}^{*}$ & $\mathbf{b}^{*}$ \\
\hline \multirow{4}{*}{ Reference color } & Compared to 1 week & 0.001 & 0.022 & 0.922 & 0.945 \\
\hline & Compared to 1 month & 0.43 & 0.999 & 0.424 & 0.741 \\
\hline & Compared to 2 months & 0.921 & 0.999 & 0.043 & 0.449 \\
\hline & Compared to 3 months & 0.002 & 0.909 & 0.041 & 0.264 \\
\hline
\end{tabular}

$\mathrm{Ca}(\mathrm{OH})_{2}$ has a truly discolorating potential, which is more apparent in cases of immature rather than mature teeth [14] [15]. According to these studies the immature teeth had been extracted for orthodontic reasons and all mature teeth for periodontal reasons, and all teeth used were anterior, free of cracks, caries, restorations or cer- 
vical abrasions, thus it is more likely that color alterations are due exclusively to the effect of the medicaments used. These studies bear some resemblance to the present one. First, the specimens were measured with a spectrophotometer, with each measurement being expressed in the CIE L*a*b* system (as in the present study). Second, their time intervals were similar to the present study (before and after placing the medicaments, and 1, 2, 4, 8 and 12 weeks after their placement). However, an important difference is that all teeth used in our study were mature. Day et al. (2011) recorded discoloration of replanted teeth after avulsion, which had been treated with $\mathrm{Ca}(\mathrm{OH})_{2}$ [16]. However, in contrast to the present study, the researchers did not mention whether the excess of the medicament in the access cavity was removed, which could have affected the crown color, while time intervals were also somewhat different (10, 60 and 90 days after placement) [16]. Furthermore, avulsed teeth probably show a degree of dentin dehydration which may enhance discoloration of such teeth; such a color alteration potential has also been reported in cases of crown fractures treated with fragment reattachment [17]. The influence of $\mathrm{Ca}(\mathrm{OH})_{2}$ on discoloration may be more severe in teeth with vital pulpal tissue, possibly because of the existence of erythrocytes which contribute to color changes after $\mathrm{Ca}(\mathrm{OH})_{2}$-induced haemolysis [18], although hemorrhage inside the pulp cavity during endodontic treatment of teeth with vital pulp is by itself sufficient to cause haemolysis [2]. However, more investigation is required in order this view to be confirmed. On the contrary, Lehnerr et al. (2012) recorded no staining neither after the use of pure $\mathrm{Ca}(\mathrm{OH})_{2}$ nor $\mathrm{Ca}(\mathrm{OH})_{2}$ pastes (both observed for a 1-year period) [3]. In this in vitro study, two hundred and ten bovine incisors were used, with color alterations being measured with a spectrophotometer and with each measurement being expressed in the CIE L*a*b* system (as in the present study). Their conclusion might be more safely taken into account, due to the larger number of specimens used, as well as the existence of more time intervals (prior to the placement of the medicaments, immediately after the placement, after 1 week, after 1, 2, 3, 6 and 12 months post-treatment). These intervals were exactly the same with the present study, with the exception of the last two ones (6 and 12 months post-treatment). Last but not least, researchers used standardized bovine tooth pieces with a similar shape and thickness (compared to human teeth), in order their results to be comparable to those of studies with human teeth.

Chlorexidine (CHX) is a really useful antimicrobial agent both for endodontic and periodontic reasons [8] [19]. It is really effective against $\mathrm{Ca}(\mathrm{OH})_{2}$-resistent bacteria (especially E. faecalis) [7] [8]. The substantivity property of CHX can last up to 12 weeks, which makes it appropriate for irrigation prior to obturation or even as an irrigant and medicament (at the same time) during retreatments [20]-[22]. However, it is highly associated with tooth staining as a side effect [10]. This is more apparent when CHX is used for periodontal reasons, and even more when dental plaque is present on the surfaces of the teeth (compared to plaque-free surfaces) [10]. Addy \& Roberts (1981) had proposed the application of alexidine instead of CHX to avoid discoloration but unfortunately they found that alexidine has a discoloring effect similar to CHX [19].

In order to combine greater antimicrobial activity with less staining effect, some researchers suggested the combination of $\mathrm{Ca}(\mathrm{OH})_{2}$ with CHX [4]-[6] [8] [9] [22]-[24], as this combination provides extensive antimicrobial effect, especially against $E$. faecalis [9]. This assumption is not widely accepted, as some researchers found that mixing CHX with $\mathrm{Ca}(\mathrm{OH})_{2}$ results in decreasing the effectiveness of $\mathrm{CHX}$ (while the properties of $\mathrm{Ca}(\mathrm{OH})_{2}$ remain unchanged) [4]-[6] [23]. However, these results are not without controversy, as all studies that have suggested a decreased antimicrobial effect of the combination chlorexidine- $\mathrm{Ca}(\mathrm{OH})_{2}$ have used chlorexidine gluconate; thus this assumption cannot be equally applied to aquatic solution of chlorexidine that it was used in the present study. This is why an aquatic solution of CHX (2\%) was selected to be combined with $\mathrm{Ca}(\mathrm{OH})_{2}$ in this study. Furthermore, CHX cannot remain alone within the root canal in vivo for a prolonged period of time, as it does not act as a physical barrier to bacteria and it does not present radiopacity [9]; thus, CHX cannot be applied as a sole intracanal medicament for such a long period of time as in the present study, and this is why the combination of $\mathrm{Ca}(\mathrm{OH})_{2}$ with $\mathrm{CHX}$ is more appropriate for long-standing use. Taken together, it seems that the combination of aquatic solution of $\mathrm{CHX}$ with $\mathrm{Ca}(\mathrm{OH})_{2}$ may indeed be a useful medicament in order to provide sufficient antimicrobial effect against E. faecalis, especially in retreatments [9]; thus, it is equally important to consider whether such a medicament may induce tooth discoloration.

The methodology used in the present study could be considered satisfactory in terms of preservation of the specimens. It has been applied by other authors in the past, too [11] [12] who found that both in the pilot group of teeth and the specimens examined that had been stored in the suggested way, tooth color alterations during time were minimal and the color remained rather stable; a similar finding was also observed in the present study. This was the reason why a larger number of teeth with no medicament was not selected for control group. 
The analysis of the CIE parameters $\left(\mathrm{L}^{*}, \mathrm{a}^{*}, \mathrm{~b}^{*}\right.$ and $\left.\Delta \mathrm{E}\right)$ supplied the study with some interesting conclusions. As mentioned above, $\mathrm{L}^{*}$ contributes to the black-to-white hue of the tooth, $\mathrm{a}^{*}$ contributes to the red-to-green hue and $b^{*}$ to the yellow-to-blue hue [12]. $\mathrm{L}^{*}$ showed a continuous increase between the four time intervals for both groups $\mathrm{A}$ and $\mathrm{B}$, which means a higher lightness of the crown of the teeth, and statistical analysis proved that this finding is statistically significant. In group A, $\mathrm{a}^{*}$ exhibited a general decrease overtime, while $\mathrm{b}^{*}$ a general increase. However, these alterations did not turn out to be statistically significant for the entire post-treatmenttime. In group $\mathrm{B}$, both $\mathrm{a}^{*}$ and $\mathrm{b}^{*}$ parameters remained at about the same levels at all four post-treatment times. The $\Delta \mathrm{E}$ values showed a general decrease in both groups between time intervals, with the final $\Delta \mathrm{E}$ values ranging between 1 and 3.3. Taking into account that $\Delta \mathrm{E}$ values below 1 concern color alterations that are not perceivable by the human eye, values between 1 and 3.3 concern alterations visually perceptible by skilled operators, and values above 3.3 concern alterations that are regarded as clinically "not acceptable", since they are probably perceivable by the patient, the values found in the present study are as clinically acceptable [13]. The fact that the type of medicament did not have a significant effect on color alteration might be explained by Lenherr et al. (2012), who showed, among others, that no significant difference was recorded between pure $\mathrm{Ca}(\mathrm{OH})_{2}$ powder and UltraCal XS, both of which were also used in the present study [3]. Nevertheless, this does not seem to be a complete explanation, as in the present study UltraCal XS was combined with CHX, but as regards $\mathrm{CHX}$, an explicit answer is not found in the literature; hence, further investigation is required.

\section{Conclusion}

$\mathrm{Ca}(\mathrm{OH})_{2}$ (either combined with $\mathrm{CHX}$ or not) has a discoloration potential. There is no significant difference between $\mathrm{Ca}(\mathrm{OH})_{2}$ and $\mathrm{Ca}(\mathrm{OH})_{2}$ combined with $\mathrm{CHX}$. Nevertheless, the period of time these medicaments remain in the root canal significantly affects their discoloration ability. Therefore, clinicians should always take esthetic considerations along with biological aspects into account before the selection of an intracanal medicament, and regard time as an important factor before the application of such medicaments.

\section{Acknowledgements}

The authors wish to thank the Department of Biomaterials of the School of Dentistry of the University of Athens for the support and the equipment provided in order the present study to be completed. They also deny any conflicts of interest related to this study.

\section{References}

[1] Krastl, G., Allgayer, N., Lenherr, P., Filippi, A., Taneja, P. and Weiger, R. (2013) Tooth Discoloration Induced by Endodontic Materials: A Literature Review. Dental Traumatology, 29, 2-7.

http://dx.doi.org/10.1111/j.1600-9657.2012.01141.x

[2] Ahmed, H.M.A. and Abbott, P.V. (2012) Discoloration Potential of Endodontic Procedures and Materials: A Review. International Endodontic Journal, 45, 883-897. http://dx.doi.org/10.1111/j.1365-2591.2012.02071.x

[3] Lenherr, P., Allgayer, N., Weiger, R., Filippi, A., Attin, T. and Krastl, G. (2012) Tooth Discoloration Induced by Endodontic Materials: A Laboratory Study. International Endodontic Journal, 45, 942-949. http://dx.doi.org/10.1111/j.1365-2591.2012.02053.x

[4] Silveira, C.F.M., Cunha, R.S., Fontana, C.E., de Martin, A.S., Gomes, B.P.F.A., Lopes Motta, R.H. and Bueno, C.E.S. (2011) Assessment of the Antibacterial Activity of $\mathrm{Ca}(\mathrm{OH})_{2}$ Combined with Chlorexidine Paste and Other Intracanal Medications against Bacterial Pathogens. European Journal of Dentistry, 5, 1-7.

[5] Carrotte, P. (2004) Endodontics: Part 9. Calcium Hydroxide, Root Resorption, Endo-Perio Lesions. British Dental Journal, 197, 735-743. http://dx.doi.org/10.1038/sj.bdj.4811897

[6] Mohammadi, Z. and Dummer, P.M.H. (2011) Properties and Applications of Calcium Hydroxide in Endodontics and Dental Traumatology. International Endodontic Journal, 44, 697-730. http://dx.doi.org/10.1111/j.1365-2591.2011.01886.x

[7] Siren, E.K., Haapasalo, M.P.P., Waltimo, T.M.T. and Orstavik, D. (2004) In Vitro Antibacterial Effect of Calcium Hydroxide Combined with Chlorexidine or Iodine Potassium on Enterococcus Faecalis. European Journal of Oral Science, 112, 326-331. http://dx.doi.org/10.1111/j.1600-0722.2004.00144.x

[8] Mohammadi, Z. and Abbott, P.V. (2009) The Properties and Applications of Chlorexidine in Endodontics. International Endodontic Journal, 42, 288-302. http://dx.doi.org/10.1111/j.1365-2591.2008.01540.x 
[9] Gomes, B.P., Vianna, M.E., Zaia, A.A., Almeida, J.F., Souza-Filho, F.J. and Ferraz, C.C. (2013) Chlorexidine in Endodontics. Brazilian Dental Journal, 24, 89-102. http://dx.doi.org/10.1590/0103-6440201302188

[10] Zanatta, F.B., Antoniazzi, R.P. and Rosing, C.K. (2010) Staining and Calculus Formation after 0.12\% Chlorexidine Rinses in Plaque-Free and Plaque Covered Surfaces. Journal of Applied Oral Science, 18, 515-521. http://dx.doi.org/10.1590/S1678-77572010000500015

[11] Koursoumis, A., Kerezoudis, N.P. and Kakampoura, A. In Vitro Assessment of Tooth Color Alteration by Two Different Types of Endodontic Irrigants. Journal of Contemporary Dental Practice (under publication).

[12] Eliades, T., Kakaboura, A., Eliades, G. and Bradley, T.G. (2001) Comparison of Enamel Colour Changes Associated with Orthodontic Bonding Using Two Different Adhesives. European Journal of Orthodontics, 23, 85-90. http://dx.doi.org/10.1093/ejo/23.1.85

[13] Seghi, R.R., Hewlett, E.R. and Kim, J. (1989) Visual and Instrumental Colorimetric Assessment of Small Color Differences on Translucent Dental Porcelain. Journal of Dental Research, 68, 1760-1764. http://dx.doi.org/10.1177/00220345890680120801

[14] Kim, S.T., Abbott, P.V. and McGinley, P. (2000) The Effects of Ledermix Paste on Discolouration of Mature Teeth. International Endodontic Journal, 33, 227-232. http://dx.doi.org/10.1046/j.1365-2591.2000.00278.x

[15] Kim, S.T., Abbott, P.V. and McGinley, P. (2000) The Effects of Ledermix Paste on Discolouration of Immature Teeth. International Endodontic Journal, 33, 233-237. http://dx.doi.org/10.1046/j.1365-2591.2000.00277.x

[16] Day, P.F., Duggal, M.S., High, A.S., Robertson, A., Gregg, T.A., Ashley, P.F., et al. (2011) Discoloration of Teeth after Avulsion and Replantation: Results from a Multicenter Randomized Controlled Trial. Journal of Endodontics, 37, 1052-1057. http://dx.doi.org/10.1016/j.joen.2011.04.014

[17] Andreasen, J.O., Andreasen, F.M. and Andersson, L. (2007) Textbook and Colour Atlas of Traumatic Injuries to the Teeth. 4th Edition, Blackwell Munksgaard, Copenhagen.

[18] Addy, M. and Moran, J. (1995) Mechanisms of Stain Formation on Teeth, in Particular Associated with Metal Ions and Antiseptics. Advances in Dental Research, 9, 450-456. http://dx.doi.org/10.1177/08959374950090041601

[19] Addy, M. and Roberts, W.R. (1981) Comparison of the Bisbiguanide Antiseptics Alexidine and Chlorexidine. II. Clinical and in Vitro Staining Properties. Journal of Clinical Periodontology, 8, 220-230. http://dx.doi.org/10.1111/j.1600-051X.1981.tb02033.x

[20] Wang, C.S., Arnold, R.R., Trope, M. and Teixeira, F.B. (2007) Clinical Efficiency of 2\% Chlorhexidine Gel in Reducing Intracanal Bacteria. Journal of Endodontics, 33, 1283-1289. http://dx.doi.org/10.1016/j.joen.2007.07.010

[21] Dametto, F.R., Ferraz, C.C., Gomes, B.P., Zaia, A.A., Teixeira, F.B. and de Souza-Filho, F.J. (2005) In Vitro Assessment of the Immediate and Prolonged Antimicrobial Action of Chlorhexidine Gel as an Endodontic Irrigant against Enterococcus faecalis. Oral Surgery, Oral Medicine, Oral Pathology, Oral Radiology and Endodontics, 99, 768-772. http://dx.doi.org/10.1016/j.tripleo.2004.08.026

[22] Rosenthal, S., Spångberg, L. and Safavi, K. (2004) Chlorhexidine Substantivity in Root Canal Dentin. Oral Surgery, Oral Medicine, Oral Pathology, Oral Radiology and Endodontics, 98, 488-492. http://dx.doi.org/10.1016/j.tripleo.2003.07.005

[23] Athanassiadis, B., Abbott, P.V. and Walsh, L.J. (2007) The Use of Calcium Hydroxide, Antibiotics and Biocides as Antimicrobial Medicaments in Endodontics. Australian Dental Journal, 52, S64-S82. http://dx.doi.org/10.1111/j.1834-7819.2007.tb00527.x

[24] Schafer, E. and Bössmann, K. (2005) Antimicrobial Efficacy of Chlorexidine and Two Calcium Hydroxide Formulations against Enterococcus faecalis. Journal of Endodontics, 31, 53-56. http://dx.doi.org/10.1097/01.DON.0000134209.28874.1C 
Scientific Research Publishing (SCIRP) is one of the largest Open Access journal publishers. It is currently publishing more than 200 open access, online, peer-reviewed journals covering a wide range of academic disciplines. SCIRP serves the worldwide academic communities and contributes to the progress and application of science with its publication.

Other selected journals from SCIRP are listed as below. Submit your manuscript to us via either submit@scirp.org or Online Submission Portal.
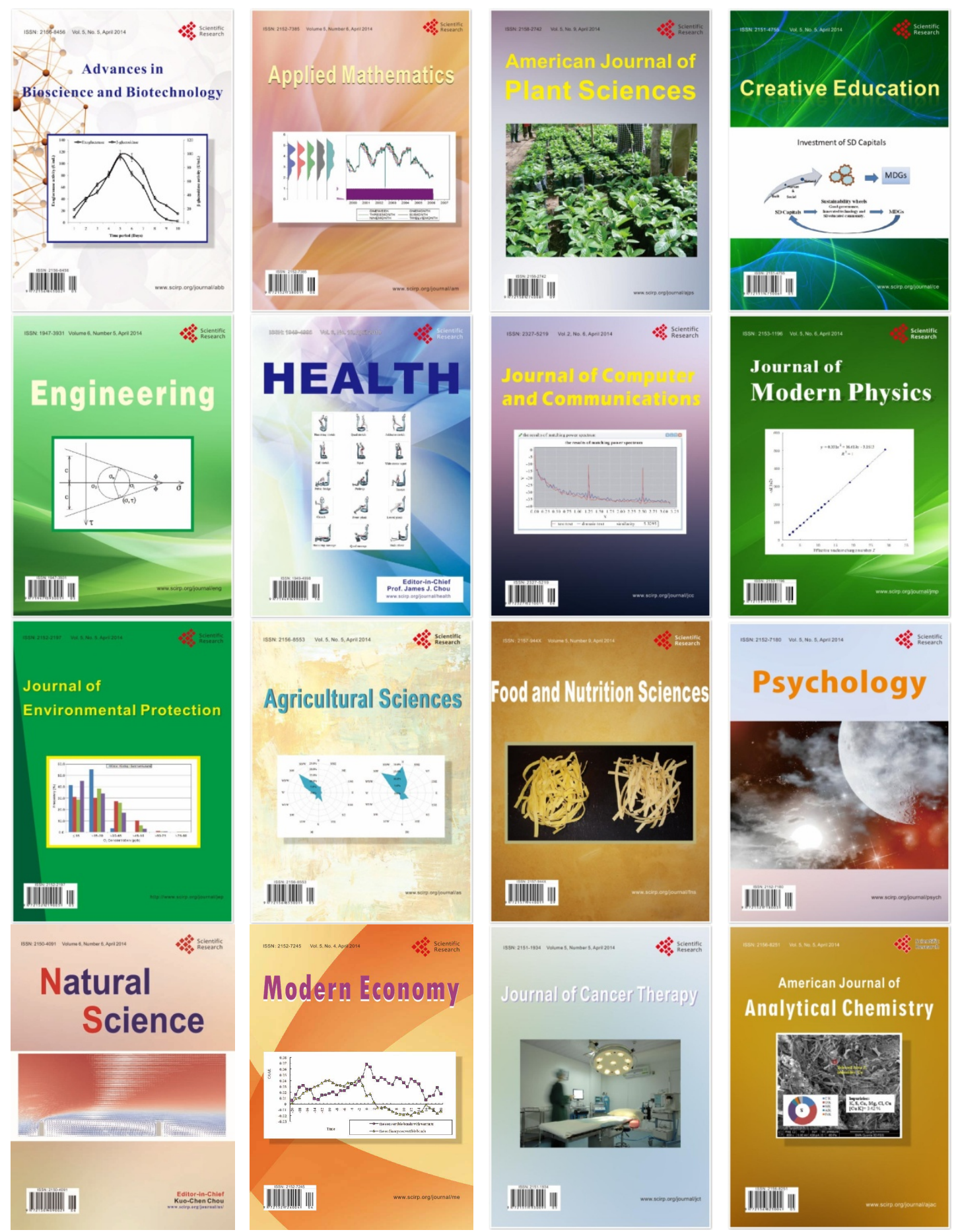